\title{
Side effects and discontinuation rate of depot medroxyprogesterone acetate in a tertiary hospital, southern Nigeria
}

\author{
Esther I. Nonye-Enyidah ${ }^{1 *}$, Ibiebelem A. Jumbo' ${ }^{1}$ Nonyenim S. Enyidah², \\ Ebbi D. Robinson ${ }^{3}$, Mazi Eke C. Ejikem ${ }^{4}$
}

\begin{abstract}
${ }^{1}$ Department of Obstetrics and Gynaecology, ${ }^{2}$ Department of Medicine, ${ }^{3}$ Department of Radiology, Rivers State University Teaching Hospital, Port Harcourt, Nigeria

${ }^{4}$ Department of Obstetrics and Gynaecology, Abia State University Teaching Hospital, Aba, Nigeria
\end{abstract}

Received: 04 September 2020

Accepted: 07 October 2020

\section{*Correspondence:}

Dr. Esther I. Nonye-Enyidah,

E-mail: hernsi@yahoo.com

Copyright: (c) the author(s), publisher and licensee Medip Academy. This is an open-access article distributed under the terms of the Creative Commons Attribution Non-Commercial License, which permits unrestricted non-commercial use, distribution, and reproduction in any medium, provided the original work is properly cited.

\begin{abstract}
Background: Depot medroxyprogesterone acetate (DMPA) also known as depo provera is a highly effective, safe and long-lasting reversible contraceptive with side effects that may cause discontinuation amongst acceptors. Objective was to determine the prevalence rate, side effects, discontinuation rate and indications for discontinuation of DMPA at Rivers State University Teaching Hospital (RSUTH), Port Harcourt.

Methods: This was a retrospective study of 874 clients attending family planning clinic at the RSUTH from $1^{\text {st }}$ January, 2015 to $31^{\text {st }}$ December, 2019. Their records were retrieved from the clinic and reviewed. Data was extracted, coded and analyzed using the statistical package for social sciences (SPSS) IBM version 25.0 (Armonk, NY).

Results: One hundred and one clients accepted DMPA out of 874 acceptors of contraceptives within the study period giving a prevalence rate of $11.6 \%$. The modal age group was 25-29 years accounting for 31 (30.7\%). Age range was 19-47 years and the modal parity was para 2. Majority of the clients had formal education, 100 (99\%), married, 94 $(93.1 \%)$ and multipara $61(60.4 \%)$. The discontinuation rate was $32.7 \%$ and the commonest reasons for discontinuation were secondary amenorrhoea and irregular vaginal bleeding with each contributing $24.2 \%$.

Conclusions: The prevalence and discontinuation rates of Depo provera were low. Secondary amenorrhoea and irregular vaginal bleeding were the commonest side effects and reasons for discontinuation.
\end{abstract}

Keywords: Depo provera, Discontinuation rate, RSUTH, Side effects

\section{INTRODUCTION}

Depo provera is a synthetic derivative of progesterone given at a dose of $150 \mathrm{mg}$ intramuscularly every 3 months. It is one of the widely used forms of contraception worldwide. ${ }^{1-3}$ The minimal service provider user attention, low Pearl index, long duration of action, simple storage and non contraceptive benefits make it suitable to use in the developing countries., ${ }^{2,4}$ Depo provera acts by primarily inhibiting gonadotrophin secretion thereby inhibiting follicular maturation and ovulation. It thickens the cervical mucus thus preventing ascent of spermatozoa into the uterine cavity. It also causes changes in the endometrium leading to endometrial atrophy thereby making implantation of fertilized ovum difficult. ${ }^{6-8}$

Depot medroxyprogesterone acetate (DMPA) like other contraceptive methods has side effects and complications which may not be acceptable to the women therefore leading to the discontinuation. ${ }^{2,3,9}$ It is notably known to cause menstrual abnormalities including secondary amenorrhoea which has a negative socio-cultural perception in our environment, irregular vaginal bleeding, 
menorrhagia and metrorrhagia. Other reported side effects are accidental pregnancies, weight gain, reduced libido, abdominal and chest pains, headaches, loss of bone mineral density, delay in return of fertility following its use, psychological and vasomotor disturbances. ${ }^{4,10}$

In view of this very effective and safe method of contraception, it becomes important to know the side effects and discontinuation rates with the reasons for the discontinuation at the Rivers State University Teaching Hospital (RSUTH), Port Harcourt. The findings will help in counselling and re-counselling of these women to encourage them not to discontinue the contraceptive in order to maximally gain from these contraceptives.

\section{METHODS}

This five year retrospective study was carried out at the family planning clinic of the Rivers State University Teaching Hospital (RSUTH) Port Harcourt, the capital of Rivers State in South-South geopolitical zone of Nigeria. The clinic gets its clients from within and outside the hospital. It has its own records section different from the hospital records and this makes it easy to retrieve the clients' case notes. The clinic is headed by a consultant family physician with the support of trained family planning nurses. Resident doctors, medical students and student nurses rotate through the clinic in batches.

At presentation, the clients were warmly welcomed by trained family planning nurses and physicians who also counseled them. The clients were allowed to make informed choice based on their needs and available contraceptives suitable for them. Thereafter medical history and clinical examination were done. Urine analysis and pregnancy test were also done for the clients and informed consent obtained. During the study period, the only available progesterone-only injectables were intramuscular injections of DMPA and Noristerat. The nurses injected $150 \mathrm{mg}$ of DMPA into the deltoid or gluteal muscle within 7 days of normal menstrual period after excluding pregnancy. It was also given six weeks post-partum in lactating mothers. Follow up observations and repeat injections were done every 90 days. At each follow up visit, every complaint is documented in their case files. The body weight, blood pressure and result of urinalysis are recorded too. A client is lost to follow up if she defaulted more than twice from the scheduled visit.

The record cards of all the clients that accepted DMPA between $1^{\text {st }}$ January, 2015 and $31^{\text {st }}$ December, 2019 were retrieved and studied. The information extracted from the cards included the socio-demographic characteristics of the clients, previous contraceptive methods used and their sources, side effects and complications of the current contraceptive, discontinuation and the reasons for discontinuation. The data was analyzed with the statistical package for social sciences (SPSS) IBM version 25.0 (Armonk, NY) using frequency counts and percentages.

\section{RESULTS}

One hundred and one clients chose DMPA out of 874 contraceptive acceptors during the study period giving the acceptance rate of $11.6 \%$. It is the $4^{\text {th }}$ most accepted contraceptive after implanon, intrauterine contraceptive device (IUCD) and jadelle. The ages of the clients ranged from 19 to 47 years. Majority of the clients, 60 (59.4\%) were between 25-34 years. The mean age was 31.2 \pm 6.0 years. Majority of the clients were multiparous women, $61(60.4 \%)$ and Christians $99(98 \%)$. The parity range was 1 to 7 and modal parity was para 2. Four (3.9\%) nullipara and $24(23.8 \%)$ grandmultipara accepted and used DMPA during the study period. One hundred (99\%) women had formal education out of which $57(56.4 \%)$ had tertiary level of education while $37(36.6 \%)$ and 6 $(6 \%)$ had secondary and primary levels of education respectively. Majority of the clients were married 94 $(93.1 \%)$ while $7(6.9 \%)$ were single. The sociodemographic characteristics of the DMPA acceptors are shown in (Table 1).

Table 1: Socio-demographic characteristics of the clients.

\begin{tabular}{|lll|}
\hline Variable & No. & Percentage (\%) \\
\hline Age (years) & \multicolumn{1}{l|}{} \\
\hline$<20$ & 11 & 1.0 \\
\hline $20-24$ & 31 & 30.9 \\
\hline $25-29$ & 29 & 28.7 \\
\hline $30-34$ & 19 & 18.8 \\
\hline $35-39$ & 9 & 8.9 \\
\hline $40-44$ & 1 & 1.0 \\
\hline $45-49$ & & \\
\hline Educational status & 1 & 1.0 \\
\hline No formal education & 6 & 6.0 \\
\hline Primary & 37 & 36.6 \\
\hline Secondary & 57 & 56.4 \\
\hline Tertiary & & \\
\hline Religion & 2 & 2.0 \\
\hline Christianity & 99 & 98.0 \\
\hline Islam & & \\
\hline Parity & 4 & 3.9 \\
\hline Nullipara & 12 \\
\hline Primipara & 11.9 \\
\hline Multipara & 61 & 60.4 \\
\hline Grand multipara & 24 & 23.8 \\
\hline Marital status & & \\
\hline Single & 7 & 6.9 \\
\hline Married & 94 & 93.1 \\
\hline
\end{tabular}

Figure 1 shows the yearly trend of acceptors of DMPA. In 2015, 2016 and 2017; 28 (12.3\%), 25 (12.4\%) and 21 $(12.6 \%)$ women accepted and used DMPA respectively. Subsequently the use continued to drop further to 13 (9.6\%) in 2018 and $14(9.9 \%)$ in 2019. 


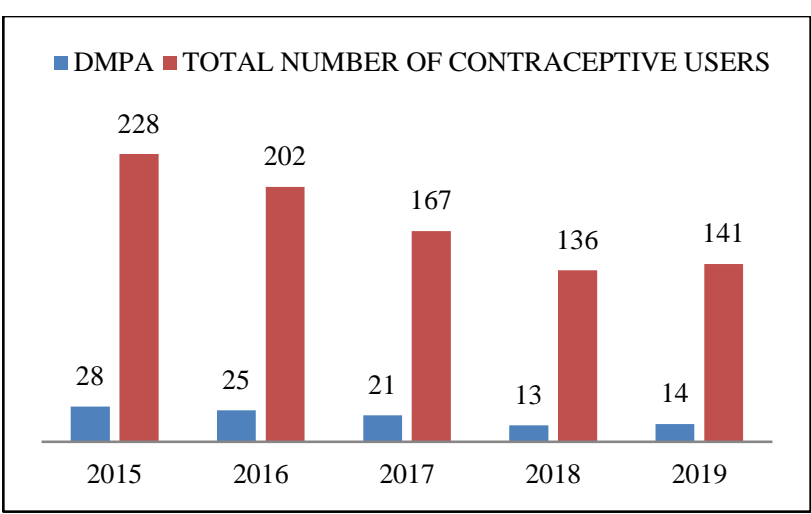

Figure 1: Yearly trend of acceptors of DMPA.

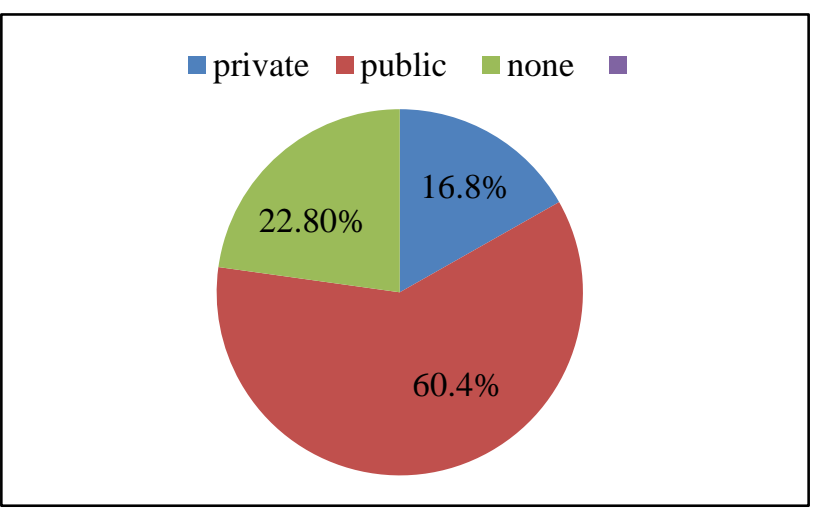

Figure 2: Sources of previous contraceptives used by clients.

Figure 2 shows the sources of previous contraceptives used by the clients. Sixty one $(60.4 \%)$ clients got their previous contraceptives from government hospitals, 17 $(16.8 \%)$ got theirs from private hospitals and $23(22.8 \%)$ did not use any form of contraceptives. Majority of the clients $(50.4 \%)$ previously used injectable contraceptives, $18(17.8 \%)$ did no use any form of contraceptives, 13 $(12.9 \%)$ previously used barrier method and $10(9.9 \%)$ used oral contraceptive pills (OCPs). This is shown in (Table 2).

Table 2: Previously used contraceptives by the clients.

\begin{tabular}{|llc|}
\hline Methods & Frequency & Percentage \\
\hline IUCD & 1 & 1.0 \\
\hline Withdrawal & 2 & 2.0 \\
\hline Calendar & 3 & 3.0 \\
\hline Postinor & 3 & 3.0 \\
\hline OCPs & 10 & 9.9 \\
\hline Barrier & 13 & 12.9 \\
\hline Injectable & 51 & 50.4 \\
\hline No method & 18 & 17.8 \\
\hline
\end{tabular}

Side effects associated with the use of DMPA which also contributed to the reasons for discontinuation of this contraceptive method are shown in Table 3. Sixty eight $(67.3 \%)$ clients did not have any complaints and did not discontinue the use of DMPA, 8 (24.2\%) clients each had secondary amenorrhoea and irregular vaginal bleeding respectively. Four (12.1\%) clients had menorrhagia and 2 $(6.1 \%)$ each had headache and lower abdominal pains respectively. Three $(9.1 \%)$ clients complained of weight gain and six (18.2\%) clients desired to get pregnant. Figure 3 shows the discontinuation rate of DMPA. Thirty three women discontinued the use of depo provera during the study period giving a discontinuation rate of $32.7 \%$. Throughout the study period there was no accidental pregnancy giving a use effectiveness of $100 \%$.

Table 3: Side effects and reasons for discontinuation of DMPA $(n=33)$.

\begin{tabular}{|ll|l|}
\hline Reasons and side effects & Frequency & Percentage \\
\hline Headache & 2 & 6.1 \\
\hline Lower abdominal pains & 2 & 6.1 \\
\hline Weight gain & 3 & 9.1 \\
\hline Menorrhagia & 4 & 12.1 \\
\hline Desire to get pregnant & 6 & 18.2 \\
\hline Irregular vaginal bleeding & 8 & 24.2 \\
\hline Secondary amenorrhoea & 8 & 24.2 \\
\hline
\end{tabular}

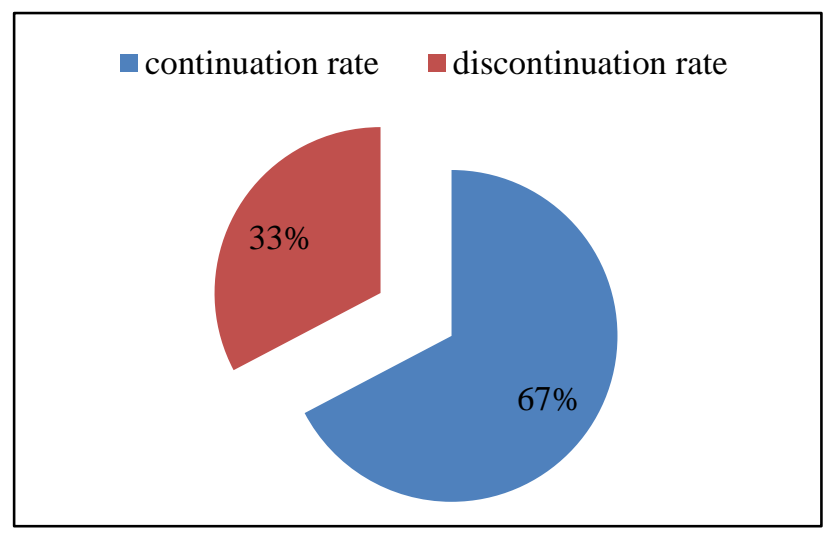

Figure 3: Continuation and discontinuation rates of DMPA.

\section{DISCUSSION}

Depo provera is the fourth most frequently accepted and used contraceptive method among women attending the family planning clinic of Rivers State University Teaching Hospital (RSUTH) following implanon, intrauterine contraceptive device (IUCD) and jadelle. In a previous study done by Nonye-Enyidah et al, it was the third frequently used contraceptive following IUCD and implanon. This result probably means that the use of DMPA is on the decline as seen in the chart or this is a smaller study compared to the previous study. ${ }^{11}$ The uptake rate of DMPA during the study period was $11.6 \%$. This is lower than $15 \%$ contraceptive prevalence rate among Nigerian women in the reproductive age group. ${ }^{12}$ It is also lower than $21.4 \%, 15.7 \%$ and $15.35 \%$ seen in similar studies done by Ezegwui et al, Abassiattai et al and Oranu et al respectively., ${ }^{4,13,14}$ The national survey 
had suggested that injectable contraceptives were the most popular and commonly accepted contraceptive method among Nigerian women. ${ }^{12}$ This is contrary to the findings in this study where DMPA was the fourth commonly accepted and used contraceptive following implanon, IUCD and jadelle. With the advent of more modern contraceptives, the uptake of DMPA in our centre has drastically reduced over the years. This is due to the long term coverage of these contraceptives like IUCD and subdermal implants which can last for five years and more. This decline in the use of DMPA is similar to findings in other centres. ${ }^{2,4}$

The mean age of the acceptors was 31.2 years. This is similar to those from previous study in southern Nigeria. ${ }^{4,10,14}$ Majority of the clients, 60 (59.4\%) were within the age range of 25 and 34 years which is in keeping with the findings from other centres. ${ }^{4,10,14}$ In this study, only one unmarried adolescent used DMPA. This might be due to the stigma attached to premarital and adolescent sex in our environment. Also adolescents prefer to patronize the chemist shop in our environment to government owned family planning clinics in other not to be seen and by the service providers. Adolescents are not advised to use progesterone-only contraceptives due to its effect on bone mineral density causing osteoporosis. ${ }^{1,15}$ They are also unlikely to be married and would benefit from abstinence or barrier methods to prevent sexually transmitted infections (STIs) as well as the contraception effects. ${ }^{8}$

Most of the clients that accepted DMPA were multipara which is in keeping with previous studies. ${ }^{4,9,10,16}$ This is because it is usually the multiparous women who seek for contraception to limit the family size and space the childbirths. ${ }^{2,3}$ This is not in keeping with studies done in southern Nigeria where most of the acceptors were grandmultipara who preferred to use DMPA for terminal contraception. ${ }^{13,14}$ Majority of the clients in this study had formal education. Several studies have confirmed the fact that contraception is more readily accepted and used by educated women. ${ }^{2,8,14}$

It is important to state that more than $60 \%$ of the clients had no side effects indicating a good safety profile of the contraceptive. Menstrual disorders were the commonest complications experienced by the clients with most of them having secondary amenorrhoea and irregular vaginal bleeding. This is in keeping with results of several studies., ${ }^{4,10,13,14}$ In this study secondary amenorrhoea and irregular vaginal bleeding were the commonest reasons for discontinuation of DMPA. These menstrual disorders are due to the effect on ovarian function. Fluctuating endogenous production from irregular follicular growth leads to irregular bleeding whereas secondary amenorrhoea has been attributed to ovarian suppression and endometrial atrophy. ${ }^{1,17}$ Secondary amenorrhoea may be beneficial to some women especially those that require reduced menstrual flow and those with sickle cell anaemia. ${ }^{18}$
Actual discontinuation rates of contraceptives vary by region, country and method of contraception. ${ }^{19}$ The discontinuation rate of DMPA in this study is $32.7 \%$. This is similar to $32.7 \%$ seen in a study done in Senegal, less than $51.5 \%$ and slightly higher than $27.1 \%$ recorded by Ezegwui at al and Danli et al respectively. ${ }^{13,19,20}$ Since Depo provera like the other contraceptives has side effects that can lead to discontinuation of the drug, it is important that health care providers should counsel the clients adequately on the benefits and side effects before and during use to reduce the discontinuation rate caused by the side effects. There was no report of accidental pregnancy while the women were on DMPA hence indicating how effective this method of contraception is. This finding is also similar to other studies. ${ }^{4,14,18}$

\section{CONCLUSION}

The acceptance rate of DMPA is low and its use is on the decline. Menstrual disorders remain the major side effects of this contraceptive and could lead to discontinuation. Therefore adequate counselling before and during follow up visits will go a long way in reducing the discontinuation rate of this very effective contraceptive.

\section{ACKNOWLEDGMENTS}

We wish to express our gratitude to the staff of the family planning clinic for the assistance rendered for this study.

Funding: No funding sources Conflict of interest: None declared

Ethical approval: The study was approved by the Institutional Ethics Committee

\section{REFERENCES}

1. Burkman R, Amnon B. Contraception and Family Planning. In: Decheney AH, ed. Current Diagnosis and Treatment Obstetrics and Gynaecology. Lange Medical Book, McGraw-Hill Companies: New York; 2013:928-47.

2. Adeyemi AS, Adekanle DA. Progestogen-only injectable contraceptive: Experience of women in Osogbo, Southwestern Nigeria. Ann Afr Med. 2012;11:27-31.

3. Igwegbe AO, Ugboaja JO. Clinical experience with injectable progestogen-only contraceptives at Nnamdi Azikiwe University Teaching Hospital, Nnewi, Nigeria. J Med Med Sci. 2010;1:345-9.

4. Oranu EO, Ojule JD, Orazulike NC. Associated factors in the declining trend in the use of progesterone only injectable contraceptive in a Niger Delta University Teaching Hospital, Nigeria. As J Med Health. 2017;3(4):1-8.

5. Malarcher S, Meirik O, Lebetkin E, Shah I, Jpieler J, Stanback J. Provision of DPMA by community health workers: What the evidence shows. Contraception. 2011;83:495-503. 
6. Darroch JE, Singh S. Trends in contraceptive need and use in developing countries in 2003, 2008, and 2012: an analysis of national surveys. Lancet. 2013;381(9879):1756-62.

7. Jacobstein R, Polis CB. Progestin only contraception: Injectables and implants. Best Pract Res Clin Obstet Gynaecol. 2014;28:795-806.

8. Nonye-Enyidah EI, Kasso T. A ten year review of Depot medroxyprogesterone acetate (DMPA) contraceptive use at Rivers State University Teaching Hospital (RSUTH), south Nigeria. Int J Adv Med. 2020;7(5):800-3.

9. Njoku CO, Emechebe CI, Iklaki CU, Njoku AN, Ukaga JT. Progestogen-only injectable contraceptives: the profile of the acceptors, side effects and discontinuation in a low resource setting, Nigeria. Open J Obstet Gynecol. 2016;6(4):189-95.

10. Ojule JD, Oriji VK, Okongwu C. A five year review of the complications of progestogen only injectable contraceptive at the University of Port Harcourt Teaching Hospital. Niger J Med. 2010;19:87-95.

11. Nonye-Enyidah E, Ejikem Mazi EC. Profile of intrauterine contraceptive device acceptors at the Rivers State University Teaching Hospital, southern Nigeria. World J Adv Res Rev. 2019;4(2):96-101.

12. National Population Commission, ICF International. Nigeria Demographic and Health Survey 2013. Abuja, Nigeria, and Rockville, Maryland, USA: NPC and ICF International; 2014:97.

13. Ezegwui HU, Ikeako LC, Obiora-Okafor NC. The use of depot medroxyprogesterone acetate injectable contraception in Enugu, Nigeria. Nigerian Med J. 2012;21:266-71.

14. Abasiattai AM, Udoma EJ, Ukeme E. Depot medroxyprogesterone injectable contraception at the
Uyo Teaching Hospital, Uyo. Ann Afr Med. 2010;9(2):81-5.

15. Okpere E. Contraception and family. In: Okpere E, ed. Clinical Gynaecology. Benin: Uniben Press; 2005:244-24.

16. Balogun OR, Raji HO. Clinical experience with injectable progestogen-only contraception at university of Ilorin Teaching Hospital: a five-year review. Nigerian Postgrad Med J. 2009;16:260-3.

17. Lisa M, Melissa G. Contraception. In: Gibbs RS, ed. Danforth's Obstetrics and Gynecology, Lippincott Williams and Wilkins, Philadelphia: USA; 2008:567-85.

18. Akadri AA, Odelola OI. Progesterone-only injectable contraceptive. Acceptor prevalence and client experience at Sagamu, Nigeria. Nigeria Postgrad Med J. 2017;24:178-81.

19. Barden-O'Fallon J, Speizer IS, Carroon M. Womens's contraceptive discontinuation and switching behaviour in urban Senegal, 2010-2015. BMC Women's Health. 2018;18:35.

20. Danli S, Qingxiang S, Guoweii S. A multicentred clinical trial of the long-acting injectable contraceptive Depo provera in Chinese women. Contraception. 2000;62(1):15-8.

Cite this article as: Nonye-Enyidah EI, Jumbo IA, Enyidah NS, Robinson ED, Ejikem MEC. Side effects and discontinuation rate of depot medroxyprogesterone acetate in a tertiary hospital, southern Nigeria. Int J Reprod Contracept Obstet Gynecol 2020;9:4834-8. 